\title{
Nanogram per Milliliter per Hour
}

National Cancer Institute

\section{Source}

National Cancer Institute. Nanogram per Milliliter per Hour. NCI Thesaurus. Code C67430.

A dose calculation unit equal to mass concentration of a substance expressed in nanograms per unit volume of one milliliter per time period of one hour. 